\title{
Learning through experiences: accessible fabricated dioramas for the visually impaired
}

\author{
Myrsini Samaroudi \\ and Karina Rodriguez Echavarria \\ Centre for Secure, Intelligent and Usable Systems, University of Brighton, UK
}

\begin{abstract}
This paper investigates digitally fabricated replicas and how these contribute as novel interpretative means to support visitor experiences in cultural heritage contexts. The paper's main contribution is the evaluation of the experience that visually impaired users had with a 3d printed relief of a Victorian environmental display, or diorama, from the Booth Museum of Natural History in Brighton (UK) along with a pervasive audio mobile application. Our intention is to illuminate the subtleties, interests and learning through experiences with objects and supporting interpretative applications in the cultural heritage sector.
\end{abstract}

Keywords: Digital fabrication - 3D printing - environmental displays · dioramas $\cdot$ visually impaired $\cdot$ museums $\cdot$ audience research.

\section{Introduction}

Digitally fabricated artefacts, or replicas, can be defined as objects that have been produced by using digital technologies and refer to or depict cultural heritage $(\mathrm{CH})$ artefacts. The production pipeline of replicas includes: a. digitally capturing the shape and appearance of an object with 3D imaging technologies; b. processing the data; and c. using fabrication technology to recreate it (e.g. with a 3D printer) and applying all necessary post-processing steps.

Over the last decades, 3D imaging technologies and consequently digital fabrication products have become popular due to reasons which are mostly related to the technology becoming more accurate, cheaper and easier to use. Following this trend, the $\mathrm{CH}$ sector has been an important field to test technologies for a variety of purposes when managing cultural heritage assets (e.g. conservation, exhibition planning, packaging and other). Amongst the most important applications of digital fabrication are these that belong to the realm of communication, information dissemination, interpretation and learning [18, 26, 27, 19].

At the same time, context-aware ubiquitous applications are gradually gaining more space in $\mathrm{CH}$ settings aiming to support users when exploring collections, based on personal information and needs $[7,6]$. Combining ubiquitous applications and the physical aspect of digitally fabricated replicas has the potential to enhance $\mathrm{CH}$ experiences in ways that were not possible before. Hence, new opportunities for accessing a more democratised cultural heritage arise $[17,18]$ 
through experiences which: allow people to become involved with the physicality of $\mathrm{CH}$ objects; embrace the "Design for All" principles [8]; aim to enhance learning and appreciation of $\mathrm{CH}$ resources, perceived in terms of a constant constructive dialogue between the individual, contextual factors and actual life connotations $[15,12,13]$. The possibilities are immeasurable if we also consider that the physical aspect of a replica can be edited and customised to satisfy specific audience groups -such as the visually impaired community- according to their requirements and circumstances [26], while being transparent and conscious about design and fabrication choices. Nonetheless, a number of questions arises regarding the effectiveness of these experiences for learning and enjoyment of cultural heritage, as it happens with the introduction of all new technologies in the $\mathrm{CH}$ sector [10].
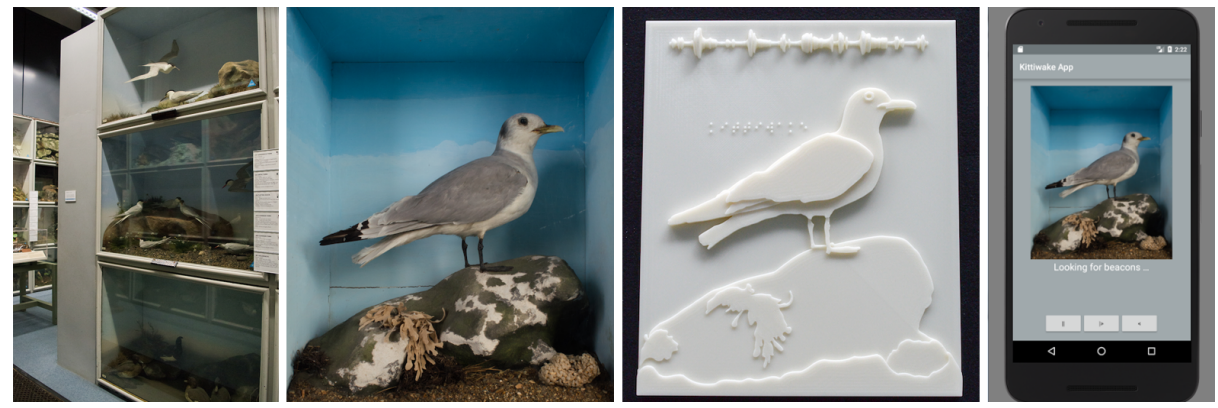

Fig. 1. a) Dioramas at the Booth Museum; b) the selected diorama; c) 3D printed relief; and d) interface of the mobile application.

This paper presents the evaluation of an experience focusing on visually impaired users interested in natural history. The research pertains to the exhibits of the Booth Museum of Natural History in Brighton (UK) and its collection of Victorian dioramas [28] which have been designated as being of national importance [24]. These dioramas are not accessible for visually impaired users as they are enclosed in glass displays (fig. 1 a). Therefore, an application was developed in order to assist visually impaired users to explore a diorama from the Booth Museum. The chosen diorama showcases a kittiwake standing on a rock and gazing across the horizon (fig. $1 \mathrm{~b}$ ). The proposed solution enables the tactile exploration a 3D printed relief (fig. 1 c) in conjunction with a context-aware audio mobile application using proximity beacons (fig. $1 \mathrm{~d}$ ). The audio description provides information about the diorama, the relief, the bird's species and the sound of the kittiwake's call. More information about the design of the relief and the application can be found in [25].

The paper is structured as follows: section 2 presents related work. Section 3 describes the case study where the relief and mobile application were deployed and the evaluation findings. Finally, section 4 presents the discussion and conclusions along with future work. 


\section{Related work}

3D replicas have already served a variety of purposes in managing $\mathrm{CH}$ resources $[26,3]$. Recently, they were also introduced to communicate $\mathrm{CH}$ information within interpretative and creative scenarios. To date, there are not many evaluation reports in literature regarding replicas in experiential frameworks. More rare are reports concerning the experience of visually impaired users.

[19] refer to an evaluation of tactile paintings given to visually impaired people. [22] talk about the qualities of tactile paintings, stating that a more comprehensive study should be planned in the future. In later evaluations of replicas with blind and partially sighted visitors, [23] assess users' feedback using both quantitative and qualitative methods focusing on materiality and interaction with replicas. In one of their latest publications, [21] evaluate a gesture-based system to experience tactile paintings. They deploy techniques of quantitative nature for the evaluation, reflecting the traditional aspects of user experience (UX). [5] similarly evaluate paintings with visually impaired users quantitatively focusing on the readability, recognition and comprehension of objects after explorations with a decreasing difficulty level. Finally, [1] evaluate a system to assist blind and partially sighted people when experiencing full 3D replicas in museums deploying observations and interviews. However, they mostly focus on usability which is measured in terms of task success, time and number of errors.

By looking at these examples it becomes understood that the evaluation of similar experiences deploying replicas is an active and interesting field of research. Our effort focuses on addressing holistically the questions around replicas and their effectiveness to support visually impaired users in novel ways.

\section{Case study}

\subsection{Evaluation design and participants}

A case study to investigate how a specific target audience responds to multiple aspects of a context-dependent $\mathrm{CH}$ experience with the use of a $3 \mathrm{~d}$ printed relief was designed. The study's target audience involved adult visually impaired participants. The evaluation took place at the Booth Museum and at the premises of the Blind Veterans charity in Brighton (fig. 2). The initial intention was to test only within the museum's context. However, soon it became obvious that this would not be feasible, as very few visually impaired people visit the museum outside of an "organised activity".

To address the questions about the contribution of the replica and application in the experience, both quantitative and qualitative data were collected. Data collection methods included video recordings, observations, questionnaires, interviews and focus groups. The topics of investigation draw on relativist constructivist theories, exploring contextual learning $[12,14,13]$ and visitor agendas in terms of personal, social and physical context. The evaluation also examines the 


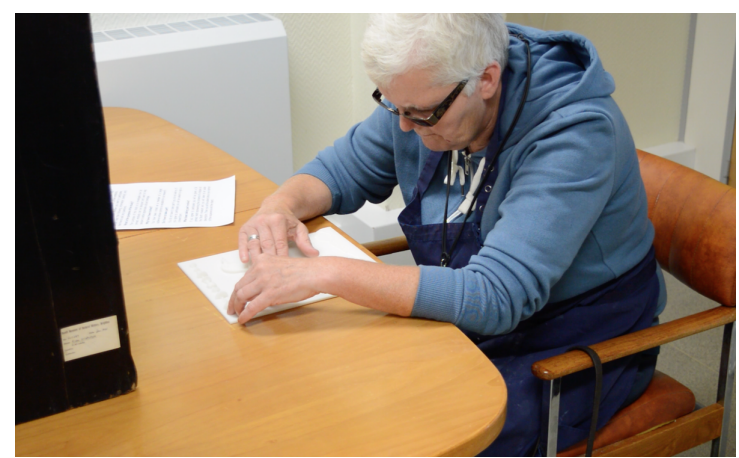

Fig. 2. Testing the relief and application with a visually impaired user.

outcome of the experience through a set of themes reflecting learning and $\mathrm{CH}$ appreciation in the broader sense as proposed -amongst others- by $[2,9]$. These refer to: awareness/knowledge; engagement/interest; attitudes; behaviours; skills.

\section{$3.2 \quad$ Findings}

The data that are analysed reflect the opinions, ideas and overall evaluation of the experience with the 3D printed relief and audio context-aware application from eleven (11) participants. For the analysis of data, we use a thematic structure focusing on the personal, social and physical context [11].

Personal context Six (6) participants were women, (two blind and four partially sighted). Men participants were five (5) (three partially sighted and two blind). All blind participants had previous sight memory. Only one participant was a Braille reader. Older ages are over-represented in the study, because most participants were members of the Blind Veterans Charity, where younger people constitute a "valuable minority" as one participant stated.

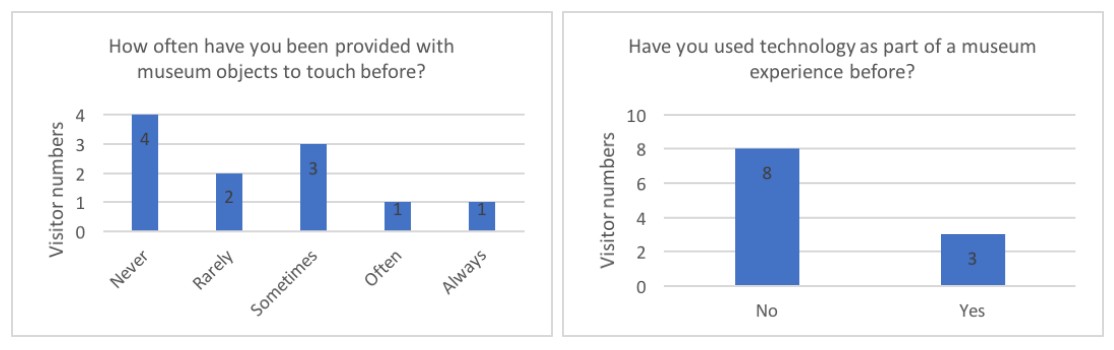

Fig. 3. a) Previous experience in touching objects; b) previous experience in using IT. 
All participants came from a white ethnic background and live in the south part of England. Participants had different levels of knowledge/experience and expectations/motivations with regards to museum visits, interaction with objects and background information. Only two (2) had visited the Booth museum in the past, even though eight (8) of them live less than fifteen (15) miles away from it. Most of the participants' past or current occupation was not related to $\mathrm{CH}$ either (only two had relevant work experience).

People had limited experience in touching objects in museums (fig. 3 a). Such finding is not surprising as only in the last decades $\mathrm{CH}$ organisations started integrating touch as a rather fundamental way to experience heritage for the visually impaired and other audience groups $[16,4]$. The only participants who had regular opportunities to touch objects were the two with relevant professional experience, hence enjoyed "privileged institutional" access to artefacts. Information technology (IT) had not been part of most people's experiences in museums either (fig. $3 \mathrm{~b}$ ). Such finding might be related to the age of participants, as two out of the three with previous IT experience in $\mathrm{CH}$ settings were of a younger age and belonged to the group of 50-59 year olds.

Table 1. Tendencies in participants' expectations.

\begin{tabular}{|l|l|}
\hline Expectations (tendencies) & Representative people's comments \\
\hline Tactile experience & $\begin{array}{l}\text { "I expected that the presentation would be different and } \\
\text { that we wouldn't find glass displays. We have got to be } \\
\text { able to touch." }\end{array}$ \\
\hline Feedback session & $\begin{array}{l}\text { "I had a vague idea of what we have done here." } \\
\text { "Touching a relief while hearing the audio description of a } \\
\text { box in front of me." }\end{array}$ \\
\hline $\begin{array}{l}\text { No expectation/Not } \\
\text { sure about it }\end{array}$ & $\begin{array}{l}\text { "I didn't really know what to expect." } \\
\text { "I had no idea." }\end{array}$ \\
\hline Find out and participate & "I am always interested in what is going on." \\
\hline Learn about 3D printing & "I am interested in 3D printing." \\
\hline
\end{tabular}

In terms of people's expectations, the intention was to find out what people were looking forward to doing during the visit or exploration. Five main tendencies have been recognised (see table 1). Most comments can be explained as the result of an organised activity. It is very rare to find in $\mathrm{CH}$ research and beyond examples of feedback collection from visually impaired users outside of an "institutional" framework. Such remark highlights the still existing societal incapacity to provide access to infrastructures for visually impaired people on a regular basis. Therefore, "outings" to museums might still impose physical and cognitive barriers for people with some kind of disability.

Quite similar are the results when examining people's interests concerning the collections of the museum. Five tendencies were noted: interest in the general 
collection; interest in the birds' collection; no specific interest; interest in fossils; interest in "whatever is accessible". For many participants visiting a museum is an opportunity to socialise and enjoy an activity that brings a change to their daily routines, without having a specific interest in the museum's collections.

Social context The first thing to examine as for the social context of the experience is the composition of each exploration. Both sessions were part of "scheduled" events. The place of the data collection dictated whether people came accompanied or not. At the Booth Museum, three out of the four participants had a volunteer who came with them, whereas at the Blind Veterans' institute all participants were on their own. In two cases, where the participants had their "helper" along, it was observed that the helper occasionally was in charge. Blind or partially sighted people were relying on them in many instances during the exploration. Helpers would often guide the participant to sit and help find the relief; motivate them to interact with it; and provide confirmation or assistance. The environment in all cases was not crowded as trials took place in pre-booked rooms. When the participants had hearing aids, external noise made listening to the audio description and focusing on it more difficult.

Physical context The physical context refers to the $\mathrm{CH}$ object itself, hence the diorama which was present in all sessions. Then, the location and its atmosphere are examined. At the Booth museum, a small room serving as storage space with shelves full of dioramas was provided. The particular smell of the museum (due to specimens) was noticeable. At the premises of the Blind Veterans, the room was in a busy area of the building. People generally seemed more comfortable in the premises of the Blind Veterans, as this was a place they knew, whereas they were relying on other people to move around at the Booth museum. Thus, even though the museum might imply a more "original" experience in spatiotemporal terms, there is a trade-off, as people are not fully confident in exploring independently exhibits and collections yet. Therefore, the portability of 3d printed replicas might be of great importance in order to facilitate access to museum content out of its physical boundaries.

Eight (8) out of the eleven (11) participants found both the exhibit and replica easily and they were attracted by it. As for the interpretative means, most people noticed the Braille label, but they did not pay much attention to it. The only participant who was a Braille reader, identified it immediately by touch and read "kittiwake" aloud. The interpretative means that participants paid most attention to are presented in fig. 4 a. Most participants paid attention both to the relief and the audio description. Those who had partial sight occasionally turned to look at the display (maybe to corroborate information). Two participants explored all means at the same time. One participant only focused on the audio and the diorama. This person, though, had enough sight to rely on it. The only participant who focused mostly on the audio, found it difficult to explore the relief while listening to the description. This person had visual memory and had not acquired tactile skills at an early stage of life. 


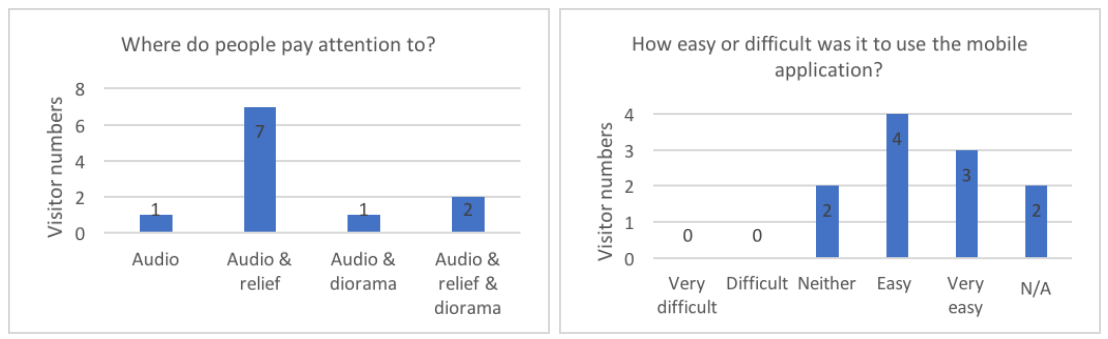

Fig. 4. a) Attraction to interpretative media; b) usability evaluation.

Regarding the usability aspect of the application, most people found it "easy" or "very easy" to use (fig. 4 b). However, phones with the application running were given to the users. Providing the devices was deemed necessary as it was not possible to know whether people had smartphones. In addition, lending devices to visitors consists a common practice for museums. Few participants found it difficult to rate the ease of use of the application, as they could not perceive how it worked since they had not done anything. Such a remark might highlight the difficulty in evaluating ubiquitous IT applications especially when involving participants of a certain age who might not be familiar with technology.

The audio description was also rated by users. Almost all of them were "satisfied" (5 out of 11) or "very satisfied" (5 out of 10) with it. Some participants commented positively about the inclusion of the actual kittiwake's call, as listening to it made the experience more complete. The soundwave representation on top of the relief was commented in various ways. Some participants could not understand its purpose, whereas others found it "novel" and "interesting". Another participant said that he would like it to have a more flexible/soft feeling.

When evaluating the features of the relief, the users were asked about its tactile properties. For sensitivity reasons, a general question about the visual appearance of the relief was included too. People were also questioned whether they would want any of the features of the relief to be changed. The majority of partially sighted people were "satisfied" or "very satisfied" with the shapes on the relief, but blind people's opinions were mixed. Few people mentioned that they found it difficult to distinguish the elements on the rock. When asked about possible changes on the relief, only one partially sighted user suggested that the representation "could be more defined with deeper detail".

As far as it concerns other comments about the relief's features, some users liked the fact that it is portable. People's opinions about the texture of the relief varied. Some were satisfied with it, whereas others wanted it to have different textures; another user expressed a desire for realistic organic textures; and one suggested using lines/dots on the seaweed and whelk eggs to differentiate them, without exaggerating as this would confuse users. As for the visual properties of the relief, two participants expressed their desire for more colour and another one stated that she would want more visual information only if the diorama was 
not present. One participant pointed out that a large print label would be useful and another one wanted some parts of the relief to be coloured in black.

The outcome-perception of the experience All qualitative data were analysed to illuminate the experience under specific themes. Inevitably there was a level of overlapping as many responses were coded under more than one themes.

Table 2. Awareness/knowledge related to the experience.

\begin{tabular}{|c|c|}
\hline \multicolumn{2}{|r|}{ Theme: Awareness/knowledge } \\
\hline Subthemes & Quotes \\
\hline Awareness & $\begin{array}{l}\text { "I thought it was interesting to actually feel and understand how } \\
\text { totally blind people can determine what they are like." }\end{array}$ \\
\hline $\begin{array}{l}\text { Making sense of some- } \\
\text { thing }\end{array}$ & $\begin{array}{l}\text { "Well the description itself gave me an understanding of what was } \\
\text { in front of me." }\end{array}$ \\
\hline $\begin{array}{l}\text { Broader understand- } \\
\text { ing }\end{array}$ & $\begin{array}{l}\text { "I like the bit where it played the sound... Before the audio played, } \\
\text { I guessed it was some form of seagull from the shape. So, it has } \\
\text { broadened that." }\end{array}$ \\
\hline $\begin{array}{l}\text { Difficulty in under- } \\
\text { standing }\end{array}$ & "Because I find this very difficult you know." \\
\hline $\begin{array}{l}\text { Using previous } \\
\text { knowledge/experience }\end{array}$ & $\begin{array}{l}\text { "... well I had a vague idea, because I've always lived by the sea. } \\
\text { So, I'm quite aware of what seabirds are like. But not the specific } \\
\text { species. I didn't know about the actual bird itself." } \\
\text { "I understand about soundwaves due to my background." }\end{array}$ \\
\hline Learning facts & "I am surprised that during the winter they go to sea." \\
\hline $\begin{array}{l}\text { Expanding informa- } \\
\text { tion }\end{array}$ & $\begin{array}{l}\text { "The only bit that wasn't mentioned in there was that there is } \\
\text { kittiwakes on, if there is any left, on Seaford Edwards." }\end{array}$ \\
\hline
\end{tabular}

People's feedback reflecting awareness, knowledge and understanding as effects of the experience ranges from making sense, to learning facts and deepening understanding about the diorama. One partially sighted user developed a better understanding (thus awareness) about blind people's interaction with objects. Other participants used previous knowledge during the identification process, while one person expanded information based on facts that he already knew. However, some people expressed a level of difficulty to perceive the relief or stated that the experience did not help them to understand better the exhibit. The main subthemes as for awareness and knowledge are presented in table 2.

The level of engagement and interest that participants demonstrated is witnessed by acts or comments related to emotions, surprise and generally the creative aspect of the experience. Observational data with regards to engagement are closely connected to people's skills. Those who were able to locate the elements on the relief often demonstrated joy or expressed themselves with affirmation sounds. Some users looked surprised when listening to the kittiwake's 
Table 3. Types of engagement with the experience.

\begin{tabular}{|c|c|}
\hline \multicolumn{2}{|r|}{ Theme: Engagement/interest } \\
\hline Subthemes & Quotes \\
\hline Using senses & $\begin{array}{l}\text { "... you were using three senses in a sense, because you are using } \\
\text { your listening skills, your feeling skills and your vision. I was using } \\
\text { all three. That was interesting." }\end{array}$ \\
\hline $\begin{array}{l}\text { Desire for creative ac- } \\
\text { tivity }\end{array}$ & $\begin{array}{l}\text { "Well I thought I was gonna come in and paint you see... But I } \\
\text { would tell them to get somebody to paint them." }\end{array}$ \\
\hline $\begin{array}{l}\text { Reminiscence/memory } \\
\text { recall }\end{array}$ & $\begin{array}{l}\text { "I used to love birds, but unfortunately I can't see them now. And } \\
\text { in my garden, I get all sorts of birds. But I can't see them, unless } \\
\text { they are very close to me. They don't do that very often." }\end{array}$ \\
\hline Feelings & "Almost felt that you are actually looking at the real thing." \\
\hline Enjoyment & $\begin{array}{l}\text { "I enjoyed the sound of what the bird made." } \\
\text { "... it didn't tell you go and explore, it took you through stage by } \\
\text { stage, which I think was better, so the guidance." }\end{array}$ \\
\hline Moderate/no interest & "As I enjoy most things. I have just enjoyed it yes." \\
\hline Surprise & $\begin{array}{l}\text { "The model of the bird and the bird itself. I think it is very pretty. } \\
\text { And that is a kittiwake?" } \\
\text { "I like the idea of actually doing the sound of the kittiwake that } \\
\text { was on top. That is a really nice idea." }\end{array}$ \\
\hline Imagination & $\begin{array}{l}\text { "And then to be able to do the description with the relief gave me } \\
\text { an understanding of putting back into a shape, back into my mind. } \\
\text { So basically, what I was able to do in the recesses of my mind, it } \\
\text { was to imagine..." }\end{array}$ \\
\hline $\begin{array}{l}\text { Connection to past in- } \\
\text { terest }\end{array}$ & $\begin{array}{l}\text { "And I love the idea of the tactile sound. But that comes because } \\
\text { of my... basically because of my background in engineering." }\end{array}$ \\
\hline
\end{tabular}

call and touching the soundwave. The users who kept tuning in and out of the relief seemed to lose and find their interest, depending on the success of the identification process. Nonetheless, they all kept coming back to the relief to engage with the exploration. Only one participant demonstrated disappointment and seemed disconnected. Further qualitative data provide more information about engagement and interest. All subthemes along with representative quotes can be found in table 3. Combining senses was something that users appreciated, while many emphasised the importance of the audio guidance. Few people did not particularly engage. Another user perceived the experience in a more emotional way, associating it with memories. The imaginative effect of the experience was also noted. Connecting enjoyment with past interests was one of the types of engagement demonstrating the power of associations with people's lives [15].

The attitudinal aspect of the experience reflects on people's principles, values, self-esteem and possible behavioural changes. To explore attitudes, participants were asked about the value of having $3 \mathrm{D}$ printed objects in museums. The resulting subthemes are presented in table 4 . Most participants recognise the 
Table 4. Attitudes related to the experience.

\begin{tabular}{|l|l|}
\hline \multicolumn{2}{|c|}{ Theme: Attitudes } \\
\hline Subthemes & Quotes \\
\hline Opinions & "When you can't see, you have got to handle something." \\
\hline Self-confidence & "It gives me much more freedom of the feeling of being part of the \\
\hline Ethical considerations & $\begin{array}{l}\text { "On the other hand, it would turn people off if they had dead birds } \\
\text { on their hands." }\end{array}$ \\
\hline $\begin{array}{l}\text { Attitudes } \\
\text { of/towards/regarding } \\
\text { organisations }\end{array}$ & $\begin{array}{l}\text { "...I do think as a visually impaired person we are not catered for, } \\
\text { "Totally encourages people to visit a museum..." }\end{array}$ \\
\hline $\begin{array}{l}\text { Attitudes } \\
\text { towards/about other } \\
\text { people }\end{array}$ & $\begin{array}{l}\text { "We need young people to be understanding the world around us." } \\
\text { "I would also like to see people who have lost their sight as adults } \\
\text { not to sit around at home, but to be able actually to do the things } \\
\text { they used to do when they had sight and still be able to enjoy them } \\
\text { and be able to access and therefore find that love back again." }\end{array}$ \\
\hline
\end{tabular}

value of handling replicas in museums. Many users, implied that $\mathrm{CH}$ organisations do not yet provide what is needed for the visually impaired. Such provision would motivate people who have lost their sight to do the things they used to enjoy, but could also help young congenitally blind people to better understand the world. In this sense, similar experiences could support basic human rights with regards to accessibility, equality and education. Interestingly, a participant mentioned the idea of "freedom" as a consequence of engaging with the relief. Lastly, one participant highlighted ethical considerations about stuffed birds' handling. An issue that replicas might be able to address.

The exploration of the relief with the support of the audio application constituted an activity through which people were challenged to use their listening, thinking and tactile skills. Some participants were skilled in combining their senses to identify the elements of the relief, following meticulously the audio description. Other users occasionally identified elements and occasionally seemed lost. However, all kept coming back to the relief to "exercise" their senses. One participant with remaining vision kept closing his eyes while navigating on the relief in an effort to isolate his listening and tactile skills from the interference of sight. Later, he referred to blindness awareness.

Participants regularly mentioned the idea of skills. Their responses detail a set of subthemes as presented in table 5. Some people found it easy to deploy many senses, while others found it challenging. One participant noted that the tactile exploration was a "new venture". As for communicating the experience, some people felt confident in explaining what had happened, while others not. Particularly interesting was the fact that some participants associated the exploration with other people's skills. One blind participant suggested that the relief 
Table 5. Skills related to the experience.

\begin{tabular}{|c|c|}
\hline \multicolumn{2}{|r|}{ Theme: Skills } \\
\hline Subthemes & Quotes \\
\hline Tactile skills & "This is a new venture. Feeling is a different finding." \\
\hline Combination of skills & $\begin{array}{l}\text { "It is difficult to have to keep moving while the description lasts." } \\
\text { "... you are using three senses in a sense, because you are using } \\
\text { your listening skills, your feeling skills and your vision." }\end{array}$ \\
\hline Communication skills & $\begin{array}{l}\text { "No, I don't think I could explain it properly, I'm sorry." } \\
\text { "I would (talk to others about the experience). Yes definitely. I think } \\
\text { it is very interesting." }\end{array}$ \\
\hline $\begin{array}{l}\text { Connecting to other } \\
\text { people's skills }\end{array}$ & $\begin{array}{l}\text { "This is the best tactile I have ever worked with. It is simplistic and } \\
\text { it would be particularly useful for blind children." } \\
\text { "I thought it was interesting to actually feel it and understand how } \\
\text { blind people can determine what they are like." }\end{array}$ \\
\hline
\end{tabular}

would be useful for blind children. Another partially sighted user felt connected to blind people in a sense of understanding their experience of the world.

The behavioural outcome of the experience highlights people's actions, lifechanges and progress connected to skill acquisition and learning. Behavioural data are closely related to skills and engagement/interest. The main subthemes regarding behaviours are presented in table 6 . Here, the analysis emphasises the importance of trialling and developing the idea of using replicas to assist visually impaired visitors. It also reflects some scepticism about the technology. However, accessing artefacts with the support of replicas is considered a positive action benefiting organisations and visually impaired visitors. Some participants also expressed a desire for learning which could be connected to future choices and actions, while another one related the experience to other people's actions. One user, who had previous experience working in $\mathrm{CH}$ settings, noted that having replicas to handle would change professional practices.

Other themes Apart from the findings that have been analysed, there are some further aspects of the experience that deserve special attention. The first one is about the importance of guidance, which is a key component for a meaningful experience. Guidance pertains to clear instructions to visually impaired visitors whenever a replica is deployed, but also refers to clearly structured material, in case there is an audio (or other) description. Another interesting idea is that of realism. Some participants expressed their desire for realistic representations of feathers and plants. Until now digital fabrication does not address adequately the need for realistic organic material representations. Further research about materials or alternative representations could provide better solutions to fulfill users' needs. Realism is also associated with the provision of full 3D replicas when that is possible. One last theme concerns the fragile nature of replicas. 
Table 6. Behaviours related to the experience.

\begin{tabular}{|c|c|}
\hline \multicolumn{2}{|r|}{ Theme: Behaviours } \\
\hline Subthemes & Quotes \\
\hline $\begin{array}{l}\text { Future trialling and } \\
\text { development }\end{array}$ & $\begin{array}{l}\text { "I would like to see how could it be developed further to be much } \\
\text { more accessible for people like myself." }\end{array}$ \\
\hline $\begin{array}{l}\text { Change in accessing } \\
\text { information and } \mathrm{CH} \\
\text { organisations }\end{array}$ & $\begin{array}{l}\text { "I would also like to see people who have lost their sight as adults } \\
\text { not to sit around at home, but to be able actually to do the things } \\
\text { they used to do when they had sight and still be able to enjoy them } \\
\text { and be able to access and therefore find that love back again." } \\
\text { "... would not only improve, but it would make the experience more } \\
\text { realistic." }\end{array}$ \\
\hline $\begin{array}{l}\text { Change in professional } \\
\text { practices }\end{array}$ & $\begin{array}{l}\text { "Very good. I would save me having to take things out of the stores } \\
\text { (he means for handling sessions)." }\end{array}$ \\
\hline Participation & $\begin{array}{l}\text { "Totally encourages people to visit a museum, but also to be part } \\
\text { of it." }\end{array}$ \\
\hline $\begin{array}{l}\text { Learning desire or } \\
\text { progression }\end{array}$ & $\begin{array}{l}\text { "Yes, well I'm always trying to learn something new." } \\
\text { "I am fascinated by the 3D printer. I'd like to get my hands on it..." }\end{array}$ \\
\hline $\begin{array}{l}\text { Action as result of the } \\
\text { experience }\end{array}$ & $\begin{array}{l}\text { "My daughter is bringing her grandson just for a week from Wor- } \\
\text { thing. I will definitely recommend that she brings him here." }\end{array}$ \\
\hline
\end{tabular}

In some instances, both officers and visitors behaved as having a valuable, fragile object in their hands when handling a replica. Such remark, might highlight a general perception about the products of digital fabrication, which in some cases seem to inherit the non-touchable features of their original "ancestors".

\section{Discussion and conclusions}

This paper discussed the evaluation of an experience where visually impaired users interacted with a 3D printed relief representing a Victorian diorama with the support of a context-aware mobile application. The potential of these types of experiences is that: they can facilitate learning and enjoyment of $\mathrm{CH}$ for a wide range of audiences through customisation in order to satisfy users' particular needs [26]; they can further contribute towards the "Design for All" principles [8]; and they provide a more democratised access to $\mathrm{CH}$ [17]. It is also important to understand that such physical-digital negotiations move beyond the digital world and place visitor's experience as the main point of interest. They also comply with the postdigital character of museums [20], while improving their relevance to society.

The results of our study demonstrate how unique an experience can be and the great perceptual variation with respect to learning, engagement, enjoyment and personal development that such experience might have as an effect. People's comments indicate that it is possible to design satisfactory experiences with the 
use of replicas. To achieve, though, the best possible outcome, $\mathrm{CH}$ professionals will have to design a holistic experience and integrate as many elements the users have positively highlighted about the physical nature of replicas and their contribution at a physical, cognitive, attitudinal and emotional level.

Future work for the research involves the enrichment of data from more users as well as the development of other studies to address questions around the physical aspect of replicas and their meaning-making implications. By doing this, a set of principles can be proposed to assist $\mathrm{CH}$ professionals when designing experiential frameworks and making decisions about the incorporation of digitally fabricated artefacts in $\mathrm{CH}$ settings and events. Such principles, could also be further developed through co-design processes when planning interpretative resources involving replicas for diverse audience groups.

\section{References}

1. Anagnostakis, G., Antoniou, M.: Accessible Museum Collections for the Visually Impaired : Combining Tactile Exploration, Audio Descriptions and Mobile Gestures. In: Proceedings of the 18th International Conference on Human-Computer Interaction with Mobile Devices and Services Adjunct. pp. 1021-1025. Italy (2016)

2. Arts Council England: Inspiring Learning for All (2014), http://www.artscouncil.org.uk/advice-and-guidance

3. Balletti, C., Ballarin, M., Guerra, F.: 3D printing: State of the art and future perspectives. Journal of Cultural Heritage 26, 172-182 (2017)

4. Candlin, F.: Museums, Modernity and the Class Politics of Touching Objects. In: Chatterjee, H.J. (ed.) Touch in Museums: Policy and Practice in Object Handling. Berg, Oxford; New York; (2008)

5. Carfagni, M., Furferi, R., Governi, L., Volpe, Y., Tennirelli, G.: Tactile Representation of Paintings: An Early Assessment of Possible Computer Based Strategies. In: Progress in Cultural Heritage Preservation, 4th International Conference, EuroMed 2012 Proceedings. vol. 7616, pp. 261-270. Springer Berlin Heidelberg (2012)

6. Chen, G., Zhang, Y., Chen, N.s.: Context-Aware Ubiquitous Learning in Science Museum with iBeacon Technology. In: Spector, J. (ed.) Learning, Design, and Technology. No. January, Springer International Publishing, Switzerland (2016)

7. Chou, S.c., Hsieh, W.t., Gandon, F., Sadeh, N., Chou, S.c., Hsieh, W.t., Gandon, F., Sadeh, N., Web, S.: Semantic Web Technologies for Context-Aware Museum Tour Guide Applications pp. 2-7 (2015)

8. Design for All Foundation: Design for All Foundation, http://designforall.org/

9. Diamond, J., Horn, M., Uttal, D.H.: Practical evaluation guide: Tools for museums and other informal educational settings. Rowman \& Littlefield Publishers (2016)

10. Economou, M.: Heritage in the Digital Age. In: Logan, W., Craith, M.N., Kockel, U. (eds.) A Companion to Heritage Studies, chap. 15. John Wiley \& Sons (2016)

11. Falk, J.: Museum audiences: A visitor-centered perspective. Loisir et Societe 39(3), 357-370 (2016)

12. Falk, J.H., Dierking, L.D.: The museum experience. Whalesback Books, Washington, D.C., 1st edn. (1992)

13. Falk, J.H., Dierking, L.D.: The Museum Experience Revisited. Left Coast Press Inc., Walnit Creek, California, 1st edn. (2013) 
14. Falk, J.H., Moussouri, T., Coulson, D.: The Effect of Visitors Agendas on Museum Learning. Curator: The Museum Journal 41(2), 107-120 (1998)

15. Hein, G.E.: John Dewey and Museum Education. Curator: The Museum Journal 47(4), 413 à 427 (2004)

16. MacDonald, S.: Exploring the Role of Touch in Connoisseurship and the Identification of Objects. In: Pye, E. (ed.) The Power of Touch: Handling Objects in Museum and Heritage Contexts. Left Coast Press Inc., California (2007)

17. Mota, C.: The rise of personal fabrication. Proceedings of the 8th ACM conference on Creativity and cognition - C\&C'11 p. 279 (2011)

18. Neely, L., Langer, M.: Please Feel the Museum: The Emergence of 3D Printing and Scanning. Museums and the Web 2013 (2013), http://mw2013.museumsandtheweb.com/paper/please-feel-the-museum-theemergence-of-3d-printing-and-scanning/

19. Neumüller, M., Reichinger, A., Rist, F., Kern, C.: 3d Printing for Cultural Heritage: Preservation, Accessibility, Research and Education. Lecture Notes in Computer Science 8355, 119-134 (2014)

20. Parry, R.: The End of the Beginning: Normativity in the Postdigital Museum. Museum Worlds 1, 24-39 (2013)

21. Reichinger, A., Fuhrmann, A., Maierhofer, S., Purgathofer, W.: Gesture-Based Interactive Audio Guide on Tactile Reliefs. In: Proceedings of the 18th International ACM SIGACCESS Conference on Computers and Accessibility - ASSETS '16. pp. 91-100 (2016)

22. Reichinger, A., Maierhofer, S., Purgathofer, W.: High-quality tactile paintings. Journal on Computing and Cultural Heritage (JOCCH) 4(2), 1-13 (2011)

23. Reichinger, A., Schröder, S., Löw, C., Sportun, S., Reichl, P., Purgathofer, W.: Spaghetti, Sink and Sarcophagus: Design Explorations of Tactile Artworks for Visually Impaired People. In: Proceedings of the 9th Nordic Conference on HumanComputer Interaction - NordiCHI '16. pp. 1-6 (2016)

24. Royal Pavilion \& Museums: Mr Booth and his Museum (2012), https://brightonmuseums.org.uk/discover/2012/11/07/

25. Samaroudi, M., Echavarria, K.R., Song, R., Evans, R.: The fabricated diorama: Tactile relief and context-aware technology for visually impaired audiences. In: Eurographics Workshop on Graphics and Cultural Heritage. The Eurographics Association, Graz (2017)

26. Scopigno, R., Cignoni, P., Pietroni, N., Callieri, M., Dellepiane, M.: Digital Fabrication Technologies for Cultural Heritage ( STAR ). In: Santos, R.K., Pedro (eds.) 12th Eurographics Workshops on Graphics and Cultural Heritage (EG GCH 2014). pp. 75-85. Eurographics Association (2014)

27. Scopigno, R., Cignoni, P., Pietroni, N., Callieri, M., Dellepiane, M.: Digital Fabrication Technologies for Cultural Heritage: A Survey. Computer Graphics Forum 36(1), 1-17 (2015)

28. Wonders, K.: Habitat dioramas as ecological theatre. European Review 1(3), 285$300(1993)$ 